\title{
Waste-plastic processing provides global challenges and opportunities
}

\author{
By Thomas Degnan \\ Feature Editor: Subhash L. Shinde
}

$\mathrm{W}$ e are drowning in plastic waste. In 2015, 9.1 metric tonnes of plastic waste flowed into our oceans. Experts predict that by 2050 , the total amount of plastic waste could amount to 850-950 metric tonnes. That will exceed the total mass of fish in the oceans. Ironically, unmanaged leaks of waste plastic into rivers and streams are only a small, though visible, part of a much more significant problem.

Major US petrochemical companies have invested heavily in ethylene and propylene production over the past decade because of the huge recent production of shale gas and natural gas liquids. Domestic US production volumes of the two largest volume plastics, polyethylene (high-density and low-density) and polypropylene are projected to grow at a compound average rate of $4.6 \%$. Globally, this growth rate is only slightly lower $(4.0 \%)$. Similar growth rates are projected for polyester $(6.0 \%)$ and polyvinylchloride $(2.3 \%)$. These volumes of virgin plastic, much of which will be used in single-use packaging, will place more duress on what is already a strained waste-handling system. Only $13 \%$ of all plastic is currently recycled $-12 \%$ by mechanical means and $1 \%$ by monomer recycling. The vast majority of plastic waste $(40 \%)$ finds its way into landfills, while another $25 \%$ is incinerated. Some of the energy value of plastic waste is recovered as power via incineration. However, analyses of current incineration practices show that the efficiency of associated energy recovery through incineration is typically low. Only about $14-28 \%$ of the energy value of the incinerated plastic is recovered as electricity. In effect, incineration has led to increased carbon emissions without the concomitant energy generation.

Up until last year, China handled approximately half of the world's recyclable waste. This all changed with the implementation of China's "National Sword" policy in January 2018. The new policy banned the import of most plastics and other materials that China had been accepting for more than a quarter of a century. China's waste-plastic imports plunged by more than $99 \%$ in the past year, producing a major shift in how the world confronts its growing waste-plastic problem.

The unsustainable nature of the current typical product life cycle of both durable and single-use plastics has not been lost on the global polymer industry. In January, approximately 30 companies banded together to establish the Alliance to End Plastic Waste (AEPW). The companies have committed to spend USD\$1.5 billion during the next five years to create solutions to eradicate plastic waste in the environment. Federal research into waste management is funded primarily through the US Environmental Protection Agency, whose budget for waste reclamation and recycling research was approximately USD\$60 million. AEPW has made plastic elimination from our oceans a particular focus. Along with research grants, the alliance will establish a worldwide open-source, science-based information and data-gathering project to underpin waste-management projects.

Several recent studies by McKinsey \& Company ${ }^{1,2}$ have pointed to opportunities to make plastic waste recovery sustainable and more profitable. McKinsey estimates that plastics reuse and recycling could be a source of as much as USD $\$ 60$ billion in additional profit for the global petrochemical and plastics sector between now and 2030. The profit would accrue, principally, from using the hydrocarbons in waste plastic as feedstocks for chemical plants and refineries rather than as material to be landfilled or burned.

Converting waste plastics back to monomers or to lower molecular weight oligomers - a process called depolymerization - offers the most significant return on investment. Sourcing hydrocarbons in this manner would potentially reduce petroleum demand for chemicals by up to $30 \%$, thereby simultaneously reducing greenhouse gas production from fossil fuels.

McKinsey's analysis, which assumes that oil sells for USD\$75/ barrel, estimates that approximately $60 \%$ of the USD $\$ 60$ billion in additional profit would come from two technical approaches: (1) conversion of poly(ethylene terephthalate) (PET) back to its raw monomers, ethylene glycol, and either terephthalic acid or dimethyl terephthalate via depolymerization, and (2) catalytic, thermal, or chemical conversion to hydrocarbon liquids and gases that could be used to replace naphtha, gas oil, and crude for ethylene cracking units or as highly valuable refining feedstocks for production of diesel or lubricants. The McKinsey analysis does not address the potential of a third approach, known as "purification," which involves using solvents and extracting dyes, solid catalysts, and additives to produce something that approximates the virgin polymer.

According to a recent report by Closed Loop Partners, ${ }^{3}$ there are approximately 100 international technology developers (United States, $52 \%$; Europe, $35 \%$; Asia, 13\%) focused on providing chemical rather than mechanical recycling solutions. Sixty of these have secured a significant number of capital investors. The majority of these startup companies are betting on technologies that are currently at or just beyond the laboratory stage. More than 40 of these technology developers are operating early-stage commercial-scale pilot plants in the United States or Canada. Several are slated to have small-scale plants operating in the next two years.

Closed Loop Partners identified 27 companies that are focused on the partial conversion of a range of plastics through advanced

Subhash L. Shinde, University of Notre Dame, USA

Thomas Degnan, Thomas.F.Degnan.11@nd.edu 
thermal or catalytic processes. These processes produce liquids and gases that are suitable as fuels or petrochemical feedstocks. Licella Holdings, an Australian-based company, has developed Cat-HTR, a catalytic hydrothermal liquefaction process that uses supercritical water $\left(250 \mathrm{bar}, 450^{\circ} \mathrm{C}\right)$ to break down a range of polymers into light hydrocarbon gases and a liquid product that resembles a high-quality, sulfur-free synthetic crude. The product can be lightly refined for use as fuel or can be used as a chemical feedstock. Licella has recently joined with Neste, a major oil refiner, and ReNew ELP, a British recycling firm. This consortium has a target to process more than 1 million tonnes/yr of waste plastic by 2030, a small fraction of the nearly 300 million tonnes of waste plastic produced each year. Advanced thermal or catalytic conversion processes such as Cat-HTR could potentially handle most of our plastic waste streams.

Meanwhile, the waste plastic industry faces several other growing technology and logistical challenges.

- None of the current technologies adequately addresses electronic componentderived waste plastics, also known as "e-plastics." These are problematic because they often contain halogens, especially brominated flame-retardants, along with metals such as silver, lead, and gold. The halogens are added to meet Underwriters Laboratories (UL) requirements.

- Current sorting and washing pro-

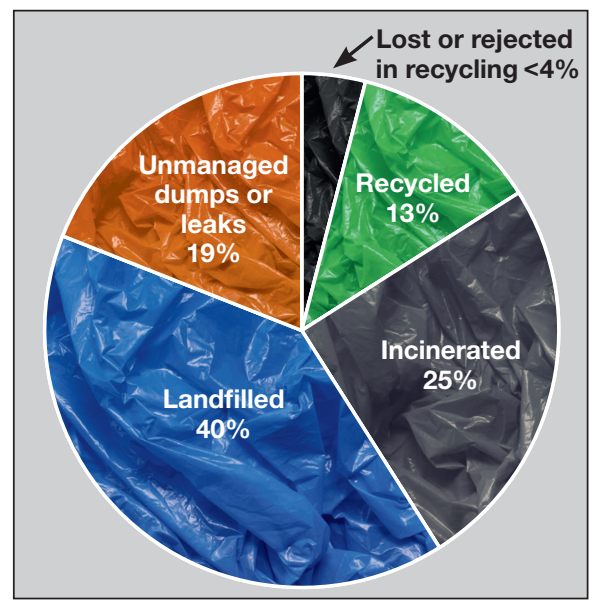

The technical challenges of plastic reprocessing. cessing technologies are not designed to handle the highly variable and often complex products (e.g., laminates) that are intrinsic to our current waste plastic streams. New technologies are needed to sort plastics beyond our current automated optical, infrared, gravimetric, and triboelectric sorting methods. Problematic plastics, such as e-plastics, labels, and metal foil-laminated bags, must be effectively identified with almost $100 \%$ accuracy before the waste stream is shredded. Improved wastewater and solvent-recovery processes are needed. - Current costs of both mechanical and chemical recycling must be reduced to be competitive with the manufacturing costs of world-scale polyethylene, polypropylene, and polyester plants. In many places, the cost of mechanical recycling, from bale to pellet, can exceed USD \$1,000/tonne. Today's reprocessing facilities have difficulty meeting waste-product recycling-quality specifications. Guidelines for the recovery and recycling of plastics waste have been stipulated by the International Organization for Standardization (ISO 15270). Quality specifications are set nationally by organizations such as UK's Resource Association.

Manufacturers are increasingly embracing waste plastics as a viable feedstock and not as a disposal problem. Initiatives such as the AEPW and increasing government regulations are likely to spur increased demand for plastic waste. Just this year, Iowa and Tennessee joined Florida, Wisconsin, and Georgia in the United States in passing legislation that incentivizes companies to reprocess more waste plastic.
Despite the increased focus on emergent depolymerization and conversion processes, the challenges to the present recycling system are likely to worsen. Material innovations, including multilayered metalized laminates, continue to increase the complexity of consumer and packaging materials. In the packaging industry, bags and pouches (flexible packaging) are among the fastest growing segments in the plastics sector. Flexible packaging often comprises plastics laminated with a thin layer of aluminum, which is intended as a barrier to oxygen and water intrusion or loss.

A study published earlier this year by the American Chemistry Council (ACC) ${ }^{4}$ predicted a near-term opportunity for US companies to invest in 260 new facilities. Capital investments will produce an estimated 38,500 new jobs that are needed to support these advanced plastic recycling and recovery facilities. ACC estimated economic benefits of USD \$2.2 billion in annual payrolls and $\$ 9.9$ billion in US economic output from these operations.

In the EU, the European Commission has acted to ban single-use plastics by 2021. A 2017 report by the European Commission $^{5}$ set out ambitious goals for greater private sector-led investment funding to finance investments in innovative solutions and new technologies aimed at reducing the environmental impacts of primary plastic production. It also recommended legislation to ensure that by 2030, all plastics packaging placed on the EU market can be reused or recycled in a cost-effective manner.

Similar initiatives are being pursued in Asia. This year, for example, India followed China in banning waste-plastic imports. Chinese universities have ramped up their research into methods for waste-plastic conversion as well as processes for producing biodegradable plastics.

Since 1990, the plastics industry, through organizations such as the American Chemistry Council, has invested more than USD \$2 billion to support increased recycling and educate communities in the United States. However, more will have to be done to ensure that we can stem the tide of waste plastics.

\section{References}

1. T.C. Hundertmark, M. Mayer, C. McNally, T.J. Simmons, C. Witte, Hydrocarbon Process. 98 (4), 9 (2019)

2. T.C. Hundermark, C. McNally, T.J. Simons, H. Vanthournout, No Time to Waste: What Plastics Recycling Could Offer (2018), www.mckinsey.com/industries/chemicals/our-insights/notimeto-waste-what-plastics-recycling-could-offer?

3. Closed Loop Partners, Accelerating Circular Supply Chains for Plastics: A Landscape of Transformational Technologies that Stop Plastic Waste, Keep Materials in Play, and Grow Markets (2019), www.closedlooppartners.com/plastics.

4. American Chemistry Council, Economic Impact of Advanced Plastics Recycling and Recovery Facilities in the U.S. (2019), https://plastics.americanchemistry.com/Economic-Impact-ofAdvanced-Plastics-Recycling-and-Recovery-Facilities-in-the-United-States.pdf.

5. European Commission, A European Strategy for Plastics in a Circular Economy (2017), http:// ec.europa.eu/environment/circular-economy/pdt/plastics-strategy-brochure.pdf. 